\title{
Clinical Efficacy of Carvedilol In Treatment of Patients With Ischemic Heart Disease and Chronic Heart Failure
}

\author{
A Jahan ${ }^{1}$, SM Ureevna ${ }^{2}$, SE Vladimirovich ${ }^{2}$ \\ ${ }^{1}$ Department of Cardiology, NICVD, ${ }^{2}$ Department of Cardiology, \\ St. Petersburg State Medical University
}

Keywords: Carvedilol, Heart failure, Ischaemic heart disease

\begin{abstract}
Background: In the pathogenesis of CHF neurohormonal changes, in particular, changes of activity of sympathetic nervous system (SNS) occupies an important position. For this reason, researchers concentrated on the use $\beta$-blockers in therapy of patients with CHF. They reduce heart rate, improve diastolic function of the myocardium, reduce secretion of renin and restore the sensitivity of $\beta$ adrenoreceptors to its regulatory influences. We studied the influence of the $3^{\text {rd }}$ generation betaadrenoblocker - Carvedilol in patients with CHF- including clinical efficacy and reduction of oxidative stress.
\end{abstract}

Methods: The study was conducted in Saint-Petersburg State Medical University, from January 2000 to June 2000. 37 patients (33 male and 4 female) with CHF class III or IV despite receiving standard therapy of heart failure were enrolled in the study for the treatment with Carvedilol. All of the patients received Carvedilol for 6 months at a dose of 12.5-50mg/day with standard therapy of Heart Failure, which was not changed during next 6 months.

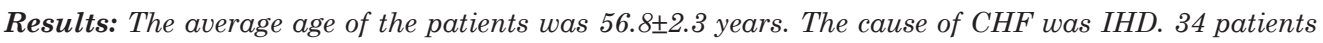
had chronic stable angina (CCS class II-IV). The majority of the patients had a history of myocardial infarction (91.8\%); of these $73.5 \%$ of the patients had a history of repeated MI. Hypertension stage 2 and 3 was associated in $32.4 \%$ patients.Long-term therapy with Carvedilol led to improvement of the clinical status of the patients. After 6 months therapy with Carvedilol frequency of hospitalization was significantly reduced $(1.36 \pm 0.23$ vs. $0.33 \pm 0.1 ; p<0,01)$. The patients were symptomatically improved after 6 months therapy with Carvedilol. There was a tendency of reduction of LV mass by $12.1 \%\left(214.0 \pm 11.1 \mathrm{gm} / \mathrm{m}^{2}\right.$ vs. $\left.188.1 \pm 10.8 \mathrm{gm} / \mathrm{m} 2, p<0.05\right)$. After treatment with Carvedilol there was significant increase in LVEF by $10 \%(30.0 \pm 1.5 \%$ to $33.0 \pm 0.1 \% ; p<0.01)$ and increase in fractional shortening of $L V$ by $22.2 \%$ (from $17.25 \pm 1.14$ vs. $21.09 \pm 1.25$; $p<0.01$ ). There was a significant reduction in plasma MDA, indicator of oxidative stress, in comparison with the baseline data.

Conclusion: Carvedilol therapy in patients with Chronic heart failure improves clinical symptoms of patients with improvement in systolic \& diastolic function of $L V$. Carvedilol also reduces oxidative stress in patients with heart failure.

(Cardiovasc. j. 2009; 1(2) : 207-215)

\section{Introduction}

Despite the doubtless success achieved in last years in the field of treatment of chronic heart failure $(\mathrm{CHF})$, many questions concerning the mechanisms of development and treatment of this syndrome require elaboration.

The significant place in the pathogenesis of $\mathrm{CHF}$ is allocated to neurohormonal changes, in particular, to changes of activity of sympathetic nervous system (SNS) and the renin angiotensin aldesterone systems (RAAS). ${ }^{1,2}$ Despite the fact that these changes initially carry a compensatory character; chronic activation of the SNS leads to increase in vascular resistance \& after load and amplification of apotosis of cardiomyocytes. It also promotes development of hypertrophy and remodeling of the myocardium and peripheral vessels. These changes in the greater degree aggravate the systolic and diastolic dysfunction of the myocardium..$^{3,4}$

For this reason, researchers concentrated on the use $\beta$-blockers in therapy of patients with $\mathrm{CHF},{ }^{5,6,7}$

Address of Correspondence: Dr Afreed Jahan, Department of Cardiology, NICVD, Dhaka, Bangladesh 
They reduce heart rate, improve diastolic function of the myocardium, reduce secretion of renin and restore the sensitivity of $\beta$-adrenoreceptors to its regulatory influences. One of the drugs of this group is Carvedilol. It is a non-selective $\beta$ and $\alpha-1$ adrenoblocker. Besides $\beta$-blocking effects, it possesses vasodilatory effect without reflex tachycardia owing to blockade of $\alpha$-1-adrenoblocker of peripheral vessels. ${ }^{8}$ In a number of researches it has been shown, that treatment with Carvedilol leads to increase in stroke volume and ejection fraction of left ventricle in patients with $\mathrm{CHF} .{ }^{9,} 10$

It is known, that $\mathrm{CHF}$ is characterized by a condition of "oxidative stress". ${ }^{11,12}$ The condition "oxidative stress" is characterized by increase of level of lipid peroxidation (LPO) products and decrease of antioxidants that have a damaging effect on cardiomyocytes. Cardioprotective effect of carvedilol also involves direct removal of free radicals from cardiomyocytes. ${ }^{13}$

For this reason, study of the influence of the $3^{\text {rd }}$ generation beta-adrenoblocker - carvedilol in patients with CHF- including clinical efficacy and reduction of oxidative stress is of interest.

Purpose of the study-1) To estimate clinical efficacy of long-term therapy with carvedilol in patients with chronic heart failure NYHA class IIIIV due to ischemic heart disease (IHD). 2) To study influence of Carvedilol on lipidperoxidation system, structural- functional parameters of heart and autonomic nervous system regulation of heart.

Study population- 37 patients (33 male and 4 female) with CHF class III or IV despite receiving standard therapy of heart failure were enrolled in the study for the treatment with carvedilol. Left ventricular ejection fraction (EF) was less than $40 \%$ (by Simpson method) and no history of treatment with beta-blockers during last 2 months. Patients were excluded from the study if any of the following was present: history of MI or unstable angina within last 6 months, uncontrolled hypertension, diabetes mellitus and rheumatic heart disease.

Methodology - The study was conducted in SaintPetersburg State Medical University, from January 2000 to June 2000. It was a open-label study. All of the patients received Carvedilol for 6 months at a dose of $12.5-50 \mathrm{mg} /$ day with standard therapy of Heart Failure. Clinical parameters of the patients like - symptomatic improvement of shortness of breath, angina, fatigue, frequency of hospitalization, functional class of patients, crepitation in lung fields, oedema, hepatic enlargement, pulse and blood pressure were evaluated before and after the study period. Effort tolerance was evaluated by 6 -minute walk test before and after carvedilol treatment. Structural and functional parameters of heart were estimated by 2D, M-mode and Doppler study on the Echo machine "Vingmed CFM-800" (Norway). Estimation of the autonomic nervous system regulation of the heart was done by determining the heart rate variability on the machine Rhythmon (Biosignal, Saint-Petersburg) at rest in standard condition. Determination of the indices of lipid peroxidation activity: the level of the plasma malondialdehyde (MDA) and superoxidedismutase (SOD) activity was investigated by spectrophotometric method.

Statistical analysis- All data analyses were carried out using statistical program "Statistica" ver.5.5A presented as $\mathrm{M} \pm \mathrm{m}$. The differences between the two treatment groups with $\mathrm{p}<0.5$ were considered statistically significant and was estimated by Mann-Whitney, Fisher, Wilcoxon tests. Correlation analyses were carried out by Spirmen and presented as coefficientr.

\section{Results:}

The average age of the patients was $56.8 \pm 2.3$ years. The cause of CHF was IHD. 34 patients had chronic stable angina (CCS class II-IV). The majority of the patients had a history of myocardial infarction (91.8\%); of these $73.5 \%$ of the patients had a history of repeated MI. Hypertension was associated in $32.4 \%$ patients.

Long-term therapy with carvedilol led to improvement of the clinical status of the patients. After 6 months therapy with carvedilol frequency of hospitalization for 6 months was significantly reduced $(1.36 \pm 0.23$ vs. $0.33 \pm 0.1 ; \mathrm{p}<0.01)$. The patients were symptomatically improved after 6 months therapy with carvedilol. The clinical feature after therapy with carvedilol in patients with CHF class III-IV improved to class II-III. Average functional class of heart failure reduced from $3.33 \pm 0.09$ to $2.33 \pm 0.1(p<0.01)$. The effort tolerance was increased with reduced shortness of breath during their performance in $54.5 \%$ 
patients $(\mathrm{p}<0.001)$. Ankle oedema and crepitation over lung fields decreased in $100 \%$ patients $(p<0.001)$. There was reduction in feeling of fatigue in $43.4 \%(p<0.001)$ and tachycardia in $34.1 \%$ patients $(\mathrm{p}<0.001)$. There was a reduction in liver size in $69.7 \%$ patients $(\mathrm{p}<0.001)$. Frequency and duration of anginal attack decreased in 79.3\% cases.

The heart rate in patients treated with carvedilol was significantly reduced but there was no bradycardia $(83.7 \pm 1.8 / \mathrm{min}$ vs. $67.3 \pm 1.5 / \mathrm{min}$, $\mathrm{p}<0.001$ ). Data on chest $\mathrm{x}$-ray showed a significant reduction in signs of pulmonary congestion in 100\% patients. Significant increase in the distance traversed by the patients during a 6 minutes walk was observed in patients after 6 months therapy with carvedilol (342.9 \pm 22.5 meter vs. $411.6 \pm 15.0$ meter, $\mathrm{p}<0.001$ ).
Left ventricular hypertrophy (LVH) was diagnosed in all patients with CHF class III-IV by echocardiographic criteria. The average value of the index of left ventricular mass before therapy was $214.0 \pm 11.1 \mathrm{gm} / \mathrm{m}^{2}$. After therapy with carvedilol, there was a tendency of reduction of this parameter by $12.1 \%\left(214.0 \pm 11.1 \mathrm{gm} / \mathrm{m}^{2} \mathrm{vs}\right.$. $188.1 \pm 10.8 \mathrm{gm} / \mathrm{m} 2, \mathrm{p}<0.05)$. After treatment with carvedilol there was significant increase in LVEF by $10 \%(30.0 \pm 1.5 \%$ to $33.0 \pm 0.1 \% ; \mathrm{p}<0.01)$ and increase in fractional shortening of $\mathrm{LV}$ by $22.2 \%$ (from 17.25 \pm 1.14 to $21.09 \pm 1.25 ; \mathrm{p}<0.01$ ). Significant reduction in $\mathrm{LV}$ systolic volume by $5.1 \%$ was observed (5.66 $\pm 0.19 \mathrm{~cm}$ vs. $5.37 \pm 0.19 \mathrm{~cm} ; \mathrm{p}<0.05)$. In patients with $\mathrm{CHF}$ class III-IV the parameters of $\mathrm{LV}$ diastolic function were not changed significantly.

Table-I

Clinical parameters of patients with CHF FC III \& IV before and after therapy with Carvedilol.

\begin{tabular}{lcc}
\hline Clinical parameters & Before therapy $(\mathrm{n}=33)$ & After Therapy $(\mathrm{n}=33)$ \\
\hline Heart rate (beats /min) & $83.7 \pm 1.8$ & $67.3 \pm 1.5 * * *(-19,6 \%)$ \\
Systolic blood pressure $(\mathrm{mm} \mathrm{Hg})$ & $133.2 \pm 4.5$ & $111.6 \pm 2.3 * * * *(-12.9 \%)$ \\
Diastolic blood pressure $(\mathrm{mm} \mathrm{Hg})$ & $83.4 \pm 2.4$ & $70.8 \pm 1.7 * * *(-15.1 \%)$ \\
6 - min walk test (meter) & $342.9 \pm 22.5$ & $411.6 \pm 15.0 * * * *(+20,0 \%)$ \\
Frequency of hospitalization over 6 months & $1.36 \pm 0.24$ & $0.33 \pm 0.10 * *(-75.7 \%)$ \\
\hline
\end{tabular}

CHF - Congestive heart failure. FC- Functional class.

*** $\mathrm{p}<0.01$,*** $\mathrm{p}<0.001$

Table-II

The Echocardiographic parameters of patients with CHF FC III \& IV before and after therapy with Carvedilol.

\begin{tabular}{lcc}
\hline Echocardiographic Parameters & Before therapy $(\mathrm{n}=33)$ & After therapy $(\mathrm{n}=33)$ \\
\hline EF $(\%)$ & $30.0 \pm 1.5$ & $33.0 \pm 1.0 * \%(+10.0 \%)$ \\
FS $(\%)$ & $17.25 \pm 1.14$ & $21.09 \pm 1.25 * * * 22.2 \%)$ \\
LVIDs $(\mathrm{cm})$ & $5.66 \pm 0.19$ & $5.37 \pm 0.19 *(-5.1 \%)$ \\
LVIDd $(\mathrm{cm})$ & $6.83 \pm 0.16$ & $6.71 \pm 0.16(-1.8 \%)$ \\
Myocardial mass index $\left(\mathrm{gm} / \mathrm{m}^{2}\right)$ & $214.0 \pm 11.1$ & $188.1 \pm 10.8(-12.1 \%)$ \\
LV mass $(\mathrm{gm})$ & $400.08 \pm 23.48$ & $357.72 \pm 24.20(-10.6 \%)$ \\
E (m/sec) & $0.78 \pm 0.04$ & $0.72 \pm 0.04(-7.7 \%)$ \\
A (m/sec) & $0.53 \pm 0.05$ & $0.73 \pm 0.18(+37.7 \%)$ \\
E/A & $1.47 \pm 0.23$ & $0.98 \pm 0.26(-33.3 \%)$ \\
IVRT (sec) & $0.12 \pm 0.008$ & $0.14 \pm 0.01(+16.7 \%)$ \\
\hline
\end{tabular}

$* \mathrm{p}<0.05, * * \mathrm{p}<0.01$

EF - Ejection Fraction, FS - Fractional shortening, LVIDd- Left ventricular internal diameter in diastole, LVIDs- Left ventricular internal diameter in systole. 


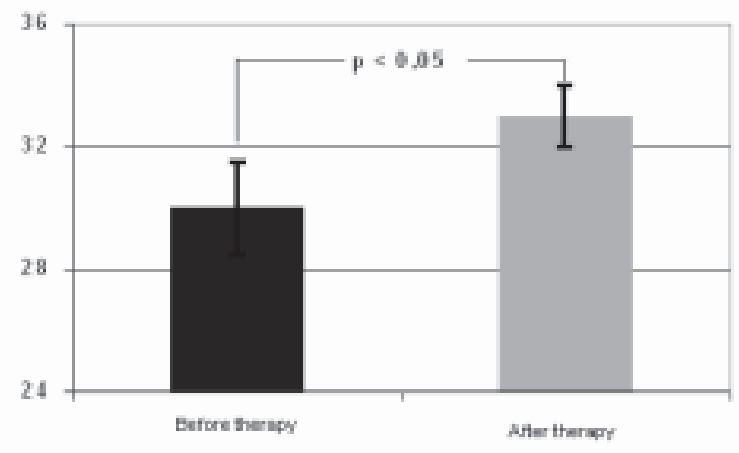

Fig 1: Left ventricular ejection fraction in patients with CHF Functional Class III \& IV on the background of therapy with carvedilol.

In analysis of heart rate variability (HRV), a significant increase in the parameters of high frequency (HF) component of the spectral analysis in patients treated with carvedilol was observed by $290.6 \%$ (from $110.4 \pm 36.0 \mathrm{~ms} 2$ to $431.3 \pm 168.0$ $\mathrm{ms} 2 ; \mathrm{p}<0.05)$. Sympathovagal index (SVI) was reduced by $50 \%$ (from $1.8 \pm 0.5$ to $0.9 \pm 0.2 ; p<0.05$ ). Due to increase in HF component of the HRV SVI in orthostatic position was reduced significantly by $30.5 \%$ in comparison with the baseline data $(3.6 \pm 1.1$ vs $2.5 \pm 0.8 ; \mathrm{p}<0.05)$. There were no significant changes in High Frequency and Low Frequency components in orthostatic position. However, there is a tendency to reduction in Low Frequency and increase in High Frequency components.



Fig 2: The parameters of high frequency components of heart rate variability in healthy population and in patients with CHF III- IV Functional Class before and after therapy with Carvedilol.

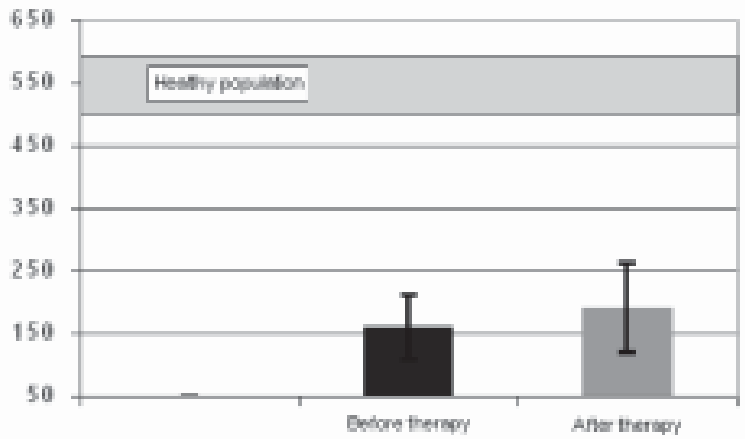

Fig 3: The parameters of low frequency components of heart rate variability in healthy population and in patients with CHF III- IV Functional Class before and after therapy with Carvedilol.

After 6-months of therapy with carvedilol in patients with CHF class III-IV, there was a significant reduction in plasma MDA in comparison with the baseline data $(14.94 \pm 0.84 \mathrm{mkmol} / \mathrm{l}$ to $12.93 \pm 1.11 \mathrm{mkmol} / \mathrm{l} ; \mathrm{p}>0.05)$. In patients with $\mathrm{CHF}$ class III-IV treated with the drug there was a tendency in reducing the level of the plasma SOD activity in comparison with the baseline $(0.32 \pm 0.03$ units in $1 \mathrm{mg}$ protein and $0.29 \pm 0.02$ units in $1 \mathrm{mg}$ protein, respectively; $\mathrm{p}>0.05$ ).

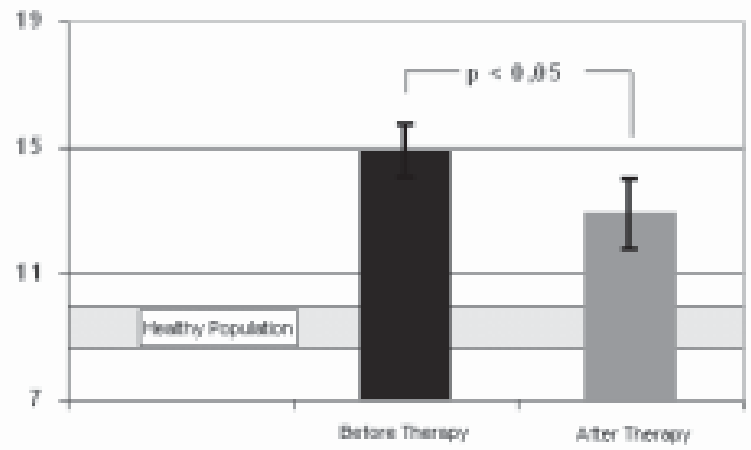

Fig 4: The plasma Malon di aldehyde (MDA) level in healthy population and in patients with $\mathrm{CHF}$ before \& after therapy with Carvedilol.

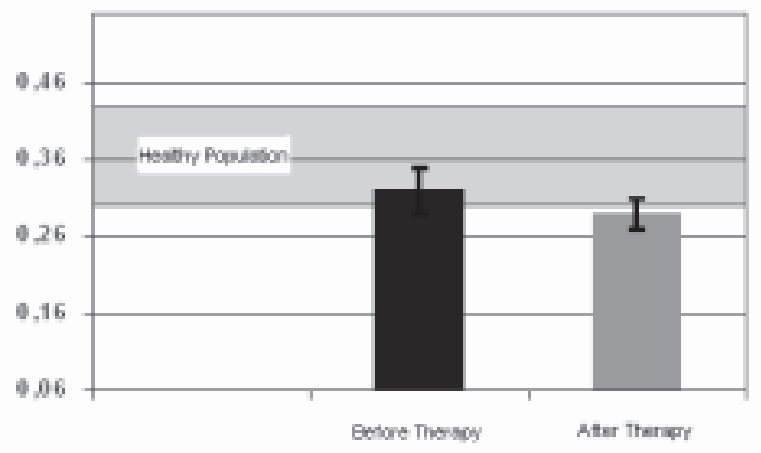

Fig 5: The plasma Super oxide dismutase (SOD) activity in healthy population and in patients with CHF before \& after therapy with Carvedilol. 


\section{Discussion:}

CHF is an evolving problem of contemporary cardiology as being a final pathway of practically all cardiovascular diseases and one of the leading causes of mortality.

For last few years, the pathophysiology of CHF has been explored. Now the great importance has been given to neurohumoral changes participating in regulation of blood circulation. ${ }^{14,15}$ The most important neurohormonal change is the changes of Sympathetic Nervous System along with renin angiotension aldosteron system. ${ }^{16,17}$ It is known that CHF is accompanied by development of oxidative stress. ${ }^{18,} 19,20$ It can aggravate contractile dysfunction of myocardium that promotes further progression of CHF. For this reason, search of preparations for effective and optimum treatment, which can reduce oxidative stress in $\mathrm{CHF}$, is important and requires further study. ${ }^{21,22}$

Inclusion of $\beta$-adrenoblocker in treatment of $\mathrm{CHF}$ is a new concept. ${ }^{5,9,15}$ Carvedilol is non-selective $\beta$ - and simultaneously $\alpha 1$-adrenoblocker. Besides its modulating influence on SNS, it also possesses cardioprotective effect by its antioxidant properties. Carvedilol and its metabolites promote removal of free radicals from cells and suppress oxidation of LDL, interfere with formation of cytotoxic and highly atherogenic forms of lipoproteins. ${ }^{13}$

In this study, the clinical efficacy of long-term (6 months) treatment with carvedilol (12.5-50 mg/ day) in patients with $\mathrm{CHF}$, its influence on structural-functional parameters of myocardium and the autonomic nervous system regulation of heart rate was studied. Also effect of carvedilol on lipid peroxidation (LPO) was evaluated in this group of patients.

Long-term treatment with carvedilol promoted improvement of effort tolerance with reduction of effort dyspnea in $54.5 \%$ patients, reduction in frequency and duration of episodes of anginal attacks. Heart rate was significantly decreased by $19.6 \%$. There was a significant reduction in NYHA functional class of CHF. Distinct clinical efficacy of carvedilol in patients with $\mathrm{CHF}$ with the above described changes have also been demonstrated in works of other authors. ${ }^{6,9,10,23-28}$
In the US Carvedilol Heart Failure Trials Program, (1996), ${ }^{29}$ patients with CHF were treated with placebo or carvedilol in doses up to $25-50 \mathrm{mg} /$ day for 6-12 months. Treatment with carvedilol improved the clinical symptoms and produced a significant improvement in NYHA functional class. S.L.Olsen et. al. also showed treatment of $\mathrm{CHF}$ with carvedilol led to significant reduction in heart rate and functional class of CHF. ${ }^{10}$

However, in ANZ-study, in patients with CHF IIII FC treatment with carvedilol in doses 25-50 $\mathrm{mg}$ /day during 6-12 months, improvements of clinical symptoms were not observed.$^{30,31}$ In $65 \%$ of the surveyed patients the clinical condition, didn't change, in $23 \%$ of patients there was clinical improvement and in $12 \%$ - deterioration of clinical symptoms of CHF was observed. In this study, the structure of the group of patients could affect the results, where $59 \%$ patients were with CHF NYHA Functional Class- II, $30 \%$ with Functional Class- I and $11 \%$ with Functional Class-III made 59\%.

An estimation of effort tolerance in patients with CHF the 6-minute walk test is widely used. It is especially convenient for an estimation of effort tolerance in patients with severe symptoms of disease, especially when opportunities of application of other objective methods are limited. ${ }^{32-34}$

There is significant increase in distance passed by patients for 6 minutes after 6 months of treatment with carvedilol has been established in comparison with the baseline data by $20.0 \%$ (from $342.9 \pm 22.47$ $\mathrm{m}$ up to $411.6 \pm 15.04 \mathrm{~m}, \mathrm{p}<0.001)$. According to the data of some authors, on a background of therapy with carvedilol, there was marked increase in walking distance of patients for 6 minutes in comparison with a baseline level..$^{9,} 35$ In other works, there was no marked influence of carvedilol on the given parameter. ${ }^{36,} 37$ The reasons of these disagreements, probably, are related to carrying out of the test in conditions of single or multicentre trials. Positive results of the given test have been received in single-centre studies where there was also observed significant improvement of quality of life of the patients. In multicentre studies there were no marked changes of this parameter. Probably, the test with 6-minute walking is reliable, when are used in conditions of single center where the patient and the researcher are more motivated for receiving of the best results. 
Spectral analysis of heart rate variability now is considered as one of the most sensitive noninvasive methods of an estimation of autonomic nervous system regulation of heart. The numerous data shows that in patients with CHF there is significant - steady reduction in the total heart rate variability. ${ }^{38,} 39$ It is a parameter of imbalance of autonomic nervous system, where activity of SNS dominates and parasympathetic activation is reduced. ${ }^{40-} 45$

In this study, in patients with CHF III-IV FC on a background of therapy with carvedilol, significant increase in parameters of HF component of the spectrum of heart rate variability by $290.6 \%$ was observed; but the power of LF component practically did not change in absolute as well as in relative units. It is the reflection of modulating influence of carvedilol on autonomic nervous system.

Analyzing the parameters of LV systolic function estimated by echocardiography, it is necessary to note that after 6-months therapy with carvedilol there was significant increase in LVEF (by 10\%), and fractional shortening (by $22.2 \%$ ). There was significant reduction in the parameters of the left ventricular end systolic volume by $5.1 \%$ from the baseline data.

Long-term therapy with carvedilol was accompanied by reduction in LV myocardial mass index by $12.1 \%$ that indicates the reduction of the degree of left ventricular hypertrophy. The changes in the parameters of the autonomic nervous system control of heart, which was revealed during therapy with carvedilol, could promote reversal of the remodeling of heart in patients with CHF IIIIV FC.

So, therapy with carvedilol led to improvement of the parameters reflecting the LV systolic function. The similar data have been received also by other authors. ${ }^{6,}$, 10,36

In majority of the patients with CHF the combination of systolic and diastolic dysfunctions of myocardium was observed. ${ }^{46,47}$

On a background of 6-months therapy with carvedilol in patients with CHF III-IV FC, the parameters of the LV diastolic function were not changed significantly, but there was some improvement of these parameters (the peak A and
IVRT have increased, peak $\AA$ and E/A have decreased). The similar data are also received by other authors. ${ }^{48-50}$ Thus; carvedilol restores the $\mathrm{LV}$ systolic function and promotes reduction in $\mathrm{LV}$ diastolic dysfunction.

The changes in the structural- functional parameters of the myocardium observed in this study indicates that carvedilol exerts positive influence on LV function not only by reducing heart rate and vasodilatation, but also due to improvement of myocardial contractility. Thus there is special value of the anti-proliferative and antioxidant actions of carvedilol on cardiomyocytes.

Increased level of plasma MDA - the basic product of LPO, ${ }^{20,51-55}$ and decreased activity of SOD, being a natural antioxidant are observed in patients with CHF. ${ }^{11,56,57}$ However, Ferrari R. and et. al. considers that there are no convincing data on interrelation of oxidative stress and severity of the CHF. ${ }^{58}$

Results of the present study demonstrate increased activity of SOD in plasma in patients with severe CHF; however, in comparison with healthy people the average values of this parameter are reduced. Besides, there is significant correlation between the level of SOD and functional class of CHF $(\mathrm{r}=0.25 ; \mathrm{p}<0.05) \&$ also left ventricular EF $(\mathrm{r}=$ $0.27 ; \mathrm{p}<0.05)$. The similar data have been received by other researchers. ${ }^{19,} 59$ It indicates the reduction of antioxidant defense system in patients with $\mathrm{CHF}$ in comparison with healthy persons. In the present study, in treatment with carvedilol, it has not been revealed significant changes of the plasma SOD activity.

In our study, the average values of plasma MDA level in patients with $\mathrm{CHF}$ in comparison with healthy people have been increased. After 6months of therapy with carvedilol in patients with CHF class III-IV, there was a significant reduction in plasma MDA in comparison with the baseline data $(14.94 \pm 0.84 \mathrm{mkmol} / \mathrm{l}$ to $12.93 \pm 1.11 \mathrm{mkmol} / \mathrm{l}$; $\mathrm{p}>0.05$ ). Reduction of plasma MDA level may be the consequence of direct antioxidant effect of the drug. ${ }^{60}$

Analysis of the dose-dependant effect of carvedilol, large doses (more than $25 \mathrm{mg} /$ day) were associated with significant improvement in clinical symptoms and LPO state. However, even small doses (less 
than $25 \mathrm{mg} /$ day) led to improvement of some investigated parameters. The received results confirm the available data about dose dependant effect of carvedilol. ${ }^{36,61}$

At an estimation of clinical efficacy of a drug, it is necessary to take into account its tolerance and safety. Tolerance of a drug is determined by frequency of occurrence of side effects on a background of the therapy, resulting in withdrawal of the given drug. In treatment with carvedilol the most frequent side effects were hypotension and dizziness, usually observed during titration period of the drug. Probably, it is related to its vasodilatory action. Similar side effects were also reported in other studies. ${ }^{6,9}$

\section{Conclusions:}

1. Long-term therapy with carvedilol led to ameliorate the clinical symptoms of heart failure class III-IV which accompanied with the increased effort tolerance.

2. Long-term therapy with carvedilol in patients with CHF class III-IV increased LV ejection fraction and fractional shortening. There was improvement of the indices of LV diastolic function.

3. Therapy with carvedilol in patients with $\mathrm{CHF}$ class III-IV reduced level of plasma malondialdehyde without changing the plasma SOD activity.

4. Carvedilol exerts a modulating effect on the indices of the HRV in patients with CHF class III-IV.

\section{Practical recommendations:}

For treatment of the patients with ischemic heart disease and chronic heart failure class IIII-IV, in addition to the standard therapy including nitrates, ACE-inhibitors, diuretics and if necessary - cardiac glycosides carvedilol may be recommended for its high clinical efficacy and safety.

\section{Conflict of Interest - None.}

\section{References:}

1 Remme W.J. Neurohormonal modulation in heart failure: ACE inhibition and beyond. Eur. Heart J 1995; 16:73-78.

2 Anker S.D., Rauchhaus M. Heart failure as a metabolic problem. Review. Eur. J. Heart Fail 1999; 1:127-131.
3 Chrysant S.G. Vascullar remodeling: The role of angiotensin-converting enzyme inhibitors.Am. Heart $J$ 1998; 135: S21-S30.

4 Cohn J.N., Johnson G. Heart failure with normal ejection fraction. Circulation 1990; 81(Suppl.- 3): 48 53.

5 CIBIS Investigations and Committees. A randomized trial of beta-blockade in heart failure: the Cardiac Insufficiency Bisoprolol Study (CIBIS). Circulation 1994; 90: $1765-1773$

6 Packer M., Colluci W.S., Sackner-Bernstein J.D., Liang C., Goldscher D.A., Freeman I. et al. Double-blind, placebo-controlled study of the effects of carvedilol in patients with moderate to severe heart failure. The PRECISE trial. Circulation 1996; 94: 2793-2799.

7 Fowler M.B., Colucci W.S., Bristow M.R., Cohn J.N, Gilbert E.M. Tolerability of carvedilol initiation in heart failure patients: Carvedilol Heart Failure Study Group. J. Am. Coll. Cardiol 1997; 29(Suppl.-A): 285.

8 Nichols A.J., Sulpizio A.C., Ashton D.J., Hieble J.P., Ruffolo R.R. In vitro pharmacologic profile of the novel beta-adrenoreceptor antagonist and vasodilator, carvedilol. Pharmacology 1989; 39: 327-336.

9 Krum H., Sackner-Bernstein J.D., Goldsmith R.L., Kukin M.L., Schwartz B., Penn J.et al. Double blind, placebo controlled study of the long term efficacy of carvedilol in patients with severe chronic heart failure. Circulation 1995; 92: 1499-1506.

10 Olsen S.L., Gilbert E.M., Renlund D.G., Mealey P.C., Taylor D.O., Yanowitz F.D. et al. Carvedilol improves left ventricular function and symptoms in chronic heart failure: A double blind randomized study. J. Am. Coll. Cardiol 1995; 25: 1225-1231.

11 Dhalla A.K., Hill M.F., Singal P.K. Role of oxidative stress in transition from hypertrophy to heart failure. J. Am. Coll. Cardiol 1996; 28:506-514.

12 Molina H., Garcia M. Enzymatic defenses of the rat heart against lipid peroxidation. Mech. Ageing Dev 1997; 97: 1-7.

13 Ruffolo R.R. Jr., Feuerstein G.Z., Pharmacology of carvedilol: rationale for use in hypertension, coronary artery disease, and congestive heart failure: Review. Cardiovasc. Drugs Ther 1997;11(Suppl.1):247-256.

14 Sidorenko B A. New approaches to the treatment of chronic heart failure. Cardiology 1998; 38(suppl-4):88-96

15 Mareev V U. The changes of the strategy of the treatment of chronic heart failure. Cardiology 1998; 12: $4-11$

16 Kiknadze M P. The Renin - angiotensin system of the heart. Cardiology 1995;35(suppl-3): 56-58.

17 Anker S.D., Rauchhaus M. Heart failure as a metabolic problem: Review. Eur. J. Heart Fail 1999;1:127-131.

18 McMurray J., Chopra M., Abdullah I., Smith W.E., Dargie H.J. Evidence of oxidative stress in chronic heart failure in humans. Eur. Heart J. 1993;14, 14931498. 
19 Ghatak A., Brar M.J., Agarwal A., Goel N., Rastogi A.K., Vaish A.K. et al. Oxygen derived free radical system in heart failure and therapeutic role of oral vitamin E. Int. J. Cardiol 1996;57:119-127.

20 Mallat Z., Phillip I., Lebret M., Chatel D., Maclouf J., Tegui A. Elevated levels of 8-iso prostaglandin $\mathrm{F}_{2 \mathrm{a}}$ in peripheral fluid of patients with heart failure. Circulation 1998; 97:1536-1539.

21 Belenkov U N. The role of systolic and diastolic dysfunction in the development of heart failure. The Therapeutic Archive 1994;66(suppl- 9): 3-7.

22 Greenberg B., Quinones M.A., Koilpillai C., Limacher M., Shindler D., Benedict C. et al. Effects of long-term enalapril therapy on cardiac structure and function in patients with left ventricular dysfunction. Results of the SOLVD echocardiography substudy. Circulation 1995; 91: 2573-2581.

23 Kelly D.T. Carvedilol in heart failure. Cardiology 1993; 82(Suppl.3.) 45-49.

24 Metra M., Nardi M., Giubbini R., Dei Gas L. Effects of short-and long-term carvedilol administration on rest and exercise hemodynamic variables, exercise capacity and clinical conditions in patients with idiopathic dilated cardiomyopathy. J. Am. Coll. Cardiol 1994; 24:16781687.

25 Colucci W.S., Packer M., Bristow M.R., Gilbert E.M., Cohn J.N., Fowler M.B. et al. Carvedilol inhibits clinical progression in patients with mild symptoms of heart failure: US Carvedilol Heart Failure Study Group. Circulation 1996;94: 2800-2806.

26 Demopoulos L., Yeh M., Gentilucci M., Testa M., Bijou R., Katz S.D. et al. Nonselective beta adrenergic blockade with carvedilol does not hinder the benefits of exercise training in patients with congestive heart failure. Circulation 1997; 95: 1764-1767.

27 Doughty R.N., Whalley G.A., Gamble G., MacMahon S., Sharpe N. Left ventricular remodeling with carvedilol in patients with congestive heart failure due to ischemic heart disease: Australia-New Zealand Heart Failure Research collaborative Group. J. Am. Coll. Cardiol 1997; 29:1060-1066.

28 Krum H. Sympathetic activation and the role of betablockers in chronic heart failure. Aust. NZ. J. Med. 1999; 29: 418-427.

29 Packer M, Bristow MR, Cohn JN, et al for the U.S. Carvedilol Heart Failure Study Group. The effect of Carvedilol on morbidity and mortality in patients with chronic heart failure. N Eng J Med 1996; 334:13491355.

30 Australia / New Zealand Heart Failure Research Collaborative Group. Randomized, placebo-controlled trial of Carvedilol in patients with congestive heart failure due to Ischaemic heart disease. Lancet 1997; 349:375-380.
31 Sharpe N., Doughty R.N. Left ventricular remodeling and improved long-term outcomes in chronic heart failure. Eur. Heart J 1998;19 (Suppl.B): B36-B39.

32 Guyatt G.H., Sullivan M.J., Thompson P.J., Fallen E.L., Pugsley S.O., Taylor D.O., Berman L.B. The 6-minute walk: a new measure of exercise capacity in patients with chronic heart failure. Can. Med. Ass. J 1985;132:919-923.

33 Roul G., Germain P., Bareiss P. Does the 6-minute walk test predict the prognosis in patients with NYHA class 2 or 3 chronic heart failure. Am. Heart J 1998; 136: 449-457.

34 Schaufelberger M., Swedberg K. Is 6-minute walk test of value in congestive heart failure. Am. Heart $J$ 1998;136: 371-372.

35 Metra M., Nodari S., D’Aloia A., Madureri A., Rosselli F., Bontempi L. et al. Effects of neurohormonal antagonism on symptoms and quality-of-life in heart failure. Eur. Heart J 1998;19( Suppl.B): B25-B35.

36 Bristow M.R., Gilbert E.M., Abraham W.T., Adams K.F., Fowler M.B., Hershberger R.E. et al. Carvedilol produces dose-related improvements in left ventricular function and survival in subjects with chronic heart failure: MOCHA Investigators. Circulation 1996; 94: 2807-2816.

37 Packer M., Bristow M.R., Cohn J.N., Colluci W.S., Fowler M.B., Gilbert E.M. et al. The effect of carvedilol on morbidity and mortality in patients with chronic heart failure: Carvedilol Heart Failure Study Group. New Engl. J. Med. 1996; 334: 1349-1355.

38 Casolo G., Balli E., Taddei T. Decreased spontaneous heart rate variability in congestive heart failure. Am. J. Cardiol 1989; 64: 1162-1167.

39 Malliani A., Pagani M., Lombardi F., Cerutti S. Cardiovascular neural regulation explored in the frequency domain. Circulation 1991; 84: 482-492.

40 Binkley P.F., Nunziata E., Haas G.J., Nelson S.D., Cody R.J. Parasympathetic withdrawal is an integral component of autonomic imbalance in congestive heart failure: demonstration in human subjects and verification in paced canine model of ventricular failure. J. Am. Coll. Cardiol. 1991; 18: 464-472.

41 Kienzle M.G., Ferguson D.W., Birkett C.l., Myers G.A., Berg W.J., Mariano D.J. Clinical, hemodynamic and sympathetic neural correlates of heart rate variability in congestive heart failure. Am. J. Cardiol. 1992; 69: 761-767.

42 Woo M.A., Stevenson W.J., Moser D.K., Middlekauff H.R. Complex heart rate variability and serum norepinephrine levels in patients with advanced heart failure. J. Am. Coll. Cardiol 1994; 23: 565-569.

43 Casolo G.C., Stroder P., Sulla A., Chelucci A., Freni A., Zerauschek M. Heart rate variability and functional severity of congestive heart failure secondary to coronary artery disease. Eur. Heart J 1995; 16: 360367. 
44 Floras J.S. Clinical aspects of sympathetic activation and parasympathetic withdrawal in heart failure. $J$. Am. Coll. Cardiol 1993; 22 (Suppl. -A): 72A-84A.

45 Dubiel J.S., Petkow-Dimitrow P., Kaluza G., Reichhart J., Brzostek T. Comparative studies of systolic and diastolic function of the left ventricle in patients with dilated cardiomyopathy. Cor Vasa 1991; 33: 227-234.

46 Litwin S.E., Grossman W. Diastolic dysfunction as a cause of heart failure: Review. J. Am. Coll. Cardiol 1993; 22 (Suppl.A): 49A-55A.

47 Bonow R.O., Udelson J.E. Left ventricular diastolic dysfunction as a cause of congestive heart failure. Mechanisms and management. Ann. Intern. Med. 1992;117: 502-510.

48 Modersohn D., Walde T., Bruch L. Diastolic heart function: pathophysiology, characterization, and therapeutic approaches: Review. Clin. Cardiol 1993; 16: $850-858$.

49 Stauffer J.C., Gaasch W.H. Recognition and treatment of left ventricular diastolic dysfunction: Review. Prog. Cardiovasc. Dis. 1990; 32:319-332.

50 Sobotka P.A., Brottman M.D., Weitz Z., Birnbaum A.J., Skosey J.L. et al. Elevated breath pentane in heart failure reduced by free radical scavenger .Free Radic. Biol. Med 1993; 14: 643-647.

51 murray $\mathrm{j}$ et al 1993

52 Diaz-Velez C.R., Garcia-Castineiras S., Mendoza-Ramos E., Hernandez-Lopez E. Increased malondialdehyde in peripheral blood of patients with congestive heart failure. Am. Heart J. 1996;131:146-152.
53 Keith M, Geranmayegan A., Sole M.J., Kurian R., Robinson A., Omran A.S. et al. Increased oxidative stress in patients with congestive heart failure. J. Am. Coll. Cardiol. 1998; 31:,1352-1356.

54 Castro P., Diaz S., Lavandero C., Nazzal C., Perez O., Arrigada G. et al. Early decrease in oxidative stress in patients with class IV heart failure after successful medical therapy. Eur. Heart J. 2000; 21: 290.

55 Singal P.K., Kirshenbaum L.A. A relative deficit in antioxidant reserve may contribute in cardiac failure. Can. J. Cardiol. 1990; 6: 47-49.

56 Landmesser U.L.F., Spiekermann S., Kohler C., Tatge H., Drexler H., Hornig B. Vascular extracelllar superoxide dismutase activity in patients with chronic heart failure. - Relationship to endothelium-dependent vasodilation: a new mechanism for endothelium dysfunction in chronic heart failure? Eur. Heart J. 2000; 21:387.

57 Ferrari R., Agnoletti L., Comini L., Gaia G., Bachetti T., Cargnoni A., Ceconi C., Curello S., Visioli O. Oxidative stress during myocardial ischemia and heart failure. Eur. Heart J. 1998; 19 (Suppl.B): B2-B11.

58 Belch J.J.F., Bridges A. B., Scott N., Chopra M. Oxygen free radicals and congestive heart failure. Br. Heart $J$. 1991; 65; 245-248.

59 Ruffolo R.R. Jr., Feuerstein G.Z. Carvedilol: preclinical profile and mechanisms of action in preventing the progression of congestive heart failure. Eur. Heart $J$ 1998; 19 (Suppl. B): B19-B24.

60 Jamal S.M., Freedman S.B., Tomson A., Carter G., Harrys P.J., Kelly D.T. Antianginal efficacy of carvedilol, a new beta blocker with vasodilating action. Cardiovasc. Pharmacol. 1997; 10: 141-146. 